\title{
Pervious concrete fill in Pearl-Chain Bridges: Using small-scale results in full-scale implementation
}

Lund, Mia Schou Møller; Hansen, Kurt Kielsgaard; Truelsen, R.; Johansen, L.

Published in:

Construction and Building Materials

Link to article, DOI:

10.1016/j.conbuildmat.2015.12.104

Publication date:

2016

Document Version

Peer reviewed version

Link back to DTU Orbit

Citation (APA):

Lund, M. S. M., Hansen, K. K., Truelsen, R., \& Johansen, L. (2016). Pervious concrete fill in Pearl-Chain Bridges: Using small-scale results in full-scale implementation. Construction and Building Materials, 106, 404414. https://doi.org/10.1016/j.conbuildmat.2015.12.104

\section{General rights}

Copyright and moral rights for the publications made accessible in the public portal are retained by the authors and/or other copyright owners and it is a condition of accessing publications that users recognise and abide by the legal requirements associated with these rights.

- Users may download and print one copy of any publication from the public portal for the purpose of private study or research.

- You may not further distribute the material or use it for any profit-making activity or commercial gain

- You may freely distribute the URL identifying the publication in the public portal 


\title{
Pervious Concrete Fill in Pearl-Chain Bridges: Using Small-Scale Results in Full-Scale Implementation
}

\author{
M. S. M. Lund*, K. K. Hansen**, R. Truelsen, L. Johansen \\ Technical University of Denmark, Department of Civil Engineering, Brovej 118, DK-2800 Kgs. Lyngby, Denmark
}

\begin{abstract}
Pearl-Chain Bridge technology is a new prefabricated arch solution for highway bridges. This study investigates the feasibility of pervious concrete as a filling material in Pearl-Chain Bridges. The study is divided into two steps: 1) small-scale tests where the variation in vertical void distribution and strength properties is determined for $800 \mathrm{~mm}$ high blocks cast in different numbers of layers, and 2) full-scale implementation in a $26 \mathrm{~m}$ long Pearl-Chain Bridge. With a layer thickness of $27 \mathrm{~cm}$, the small-scale tests indicated homogenous results; however, for the full-scale implementation, the same degree of homogeneity was not shown.
\end{abstract}

Keywords: Filling material, Pearl-Chain Bridge, Pervious concrete, Strength property, Vertical void distribution

\section{Introduction}

Pearl-Chain Bridge technology introduces an innovative arch solution for highway bridges (Halding et al., 2015b). Despite its optimal shape, the arch is rarely used for highway bridges because of the extensive need for scaffolding that closes down the highway for weeks. With the Pearl-Chain Bridge technology, the highway is closed for a minimum period of time, which reduces traffic disturbances and carbon dioxide emissions. Furthermore, the material consumption is minimized due to the optimal arch shape. The Pearl-Chain arch is created by collecting and post-tensioning several Super-Light Decks on a wire, like pearls on a string. Subsequently a crane is used to lift the arch into place (Halding et al., 2015a). When the arch is placed, spandrel walls are installed and a filling material is laid out. The first Pearl-Chain Bridge ever built was constructed in 2015. Crossing Vorgod Stream in Jutland, Denmark, and connecting two gravel roads on each side, the bridge load is classified for 50 tonnes (DS Standard 1991-2, 2003; DS Standard 1991-2 DK NA, 2003). The bridge consists of a $13 \mathrm{~m}$ long arch and two 6.5 $\mathrm{m}$ long adjacent half arches as shown in Figure 1. This gives the bridge a total span length of $26 \mathrm{~m}$. The width of the bridge is $6.1 \mathrm{~m}$ and the pile height is $0.9 \mathrm{~m}$.

The filling material in the bridge is shown as shaded areas in Figure 1. The maximum placing depth of the filling material is $0.9 \mathrm{~m}$ and the filling material has a total volume of $45 \mathrm{~m}^{3}$.

Portland cement pervious concrete (PCPC) is a concrete with a significant void content-typically 11-35\% (Schaefer et al., 2006) — which gives it excellent drainage properties. Typically, the fill in arch bridges is cast with a granular material; how-

\footnotetext{
*Corresponding author. Tel.: +45 45251752

** Tel.: +4545251826

Email addresses: msml@byg.dtu.dk (M. S. M. Lund), kkh@byg.dtu.dk (K. K. Hansen)
}

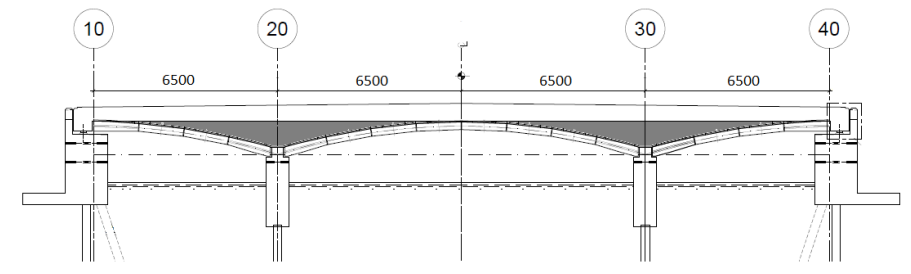

Figure 1: Longitudinal section of Pearl-Chain Bridge over Vorgod Stream. The shaded areas mark the location of pervious concrete filling material. Dimensions are in $\mathrm{mm}$.

ever, for the Pearl-Chain Bridge shown in Figure 1, PCPC was chosen as the filling material because of several considerations:

1. PCPC fill is expected to contribute positively to the lifetime of the bridge. A bridge is a sensitive point in a road construction because it is exposed to freezing from below as well as from above. The lower permeability of typical unbound filling materials such as gravel and soil may cause water accumulation, leading to potential frost damages when the bridge freezes. Using PCPC as a filling material improves arch bridge durability because such water accumulation is entirely prevented due to the large permeability of PCPC.

2. PCPC fill can be incorporated structurally because the strength properties are significantly improved compared to unbound filling materials. This means, for example, that the fill material is able to transfer shear stresses.

3. PCPC fill is easier to cast than typical unbound filling materials that need to be compacted in layers of $30 \mathrm{~cm}$ in thickness. It is expected that it is possible to design a selfcompacting PCPC mix that can simply be cast by pouring it onto the arch in a single lift and only compact it from the top. However, this is outside the scope of the present study. 
For the use of PCPC as fill in Pearl-Chain Bridges it is required that the 28-days compressive strength and the 28-days splitting tensile strength are minimum $10 \mathrm{MPa}$ and $1 \mathrm{MPa}$, respectively. Furthermore, the freeze-thaw durability of the PCPC fill should be good. The permeability should be at least $0.65 \times 10^{4} \mathrm{~cm} / \mathrm{s}$ since this corresponds to the maximum intensity of a rain event in Denmark with 10 year return period assuming that the rain falls in a 24 hours period (Regional variation of extreme rain in Denmark - a new analysis 1979-2005, 2006). Without compromising the quality of PCPC it is desired that the mentioned strength and durability requirements are fulfilled with the highest possible void content to keep the PCPC cost at a minimum.

While the literature proves it is possible to design a PCPC mixture that meets filling material strength and durability requirements, such research is lacking on PCPC placed at high depths. The present paper investigates the use of PCPC as a fill in Pearl-Chain Bridges. Small-scale tests where PCPC is placed in layers of up to $800 \mathrm{~mm}$ serves three main purposes:

1. To investigate the feasibility of casting homogeneous pervious concrete in layers of up to $0.8 \mathrm{~m}$.

2. To identify a suitable compaction method.

3. To determine the strength properties-compressive strength, Young's modulus, splitting tensile strength, and shear strength - and the variation of these strength properties through a $0.8 \mathrm{~m}$ deep pervious concrete layer.

Based on the findings and conclusions from the laboratory tests, PCPC is implemented as fill in the Pearl-Chain Bridge over Vorgod Stream in Denmark. The experiences, results and conclusions from this are also described herein.

\section{Background}

PCPC consists of cement, water, and a single-sized coarse aggregate that is used to maximize the void content. PCPC has less cement paste than conventional Portland cement concrete, which leaves space for the interconnected void structure. The cement paste typically has a low water-to-cement $(\mathrm{w} / \mathrm{c})$ ratio of 0.27-0.34, which causes stiff PCPC workability. The strength of PCPC increases significantly when substituting up to $7 \%$ of the coarse aggregate with sand (Kevern et al., 2008). Using chemical admixtures such as air entrainment (AEA), superplasticizers, and hydration stabilizers also improves strength properties and freeze-thaw durability (Kevern et al., 2008; NRMCA, 2004). Tests have shown that in order to obtain the best PCPC durability the AEA dosage should correspond to the use in regular concrete, whereas the retarder dosage should be much higher (Schaefer and Kevern, 2011).

There is a linear correlation between the void content and the density of PCPC (Kevern et al., 2008). PCPC strength properties are strongly related to the void content and therefore to the density, and 28-days compressive strength values of 5.5-32 $\mathrm{MPa}$ are reported (Schaefer et al., 2006). As far as can be ascertained, very little information about Young's modulus of PCPC is published, although studies have reported a static modulus of elasticity of 13-32 GPa for void contents of 15-35\% (Crouch et al., 2007). Permeability coefficients of $0.20-0.54 \mathrm{~cm} / \mathrm{s}$ are most common (Tennis et al., 2004). The freeze-thaw durability of PCPC is typically tested according to the American Society for Testing and Materials (ASTM) C666 standard (ASTM Standard C666, 2008). However, several examples have shown that air-entrained PCPC performs much better in the field than in the laboratory, where the test method is often considered to be a worst-case scenario and not representative of on-site behavior, since drainage is not taken into account (Henderson and Tighe, 2012; Kevern et al., 2009). In the field, PCPC pavements perform well over several years in areas that undergo a large number of annual freeze-thaw cycles, provided it remains unsaturated (NRMCA, 2004).

PCPC is typically used for pavements as it helps reduce storm-water runoff (Tennis et al., 2004). This implies that its placing depth is rarely particularly large. In the field, PCPC is typically placed in a single lift followed by compaction from the top. This produces a vertical void distribution variation with the lowest content at the top of the layer and the highest at the bottom. The distribution of the void content and hence the properties of PCPC are highly dependent on the compaction method (Haselbach and Freeman, 2006).

\section{Experimental Method}

In the small-scale tests, pervious concrete was mixed and cast in $0.8 \mathrm{~m}$ high molds with a volume of $1 \mathrm{~m}^{3}$ at two different Danish mixing plants, mixing plant $\mathrm{A}$ and mixing plant B. Different layer thicknesses were investigated to determine which was most appropriate for full-scale implementation. Table 1 summarizes the outline of the experimental plan for the small-scale tests.

Table 1: Outline of experimental plan for small-scale tests.

\begin{tabular}{l|cc}
\hline & Mix no. 1 & Mix no. 2 \\
\hline Place & $\begin{array}{c}\text { Mixing plant A } \\
\text { Sep. 29, 2014 }\end{array}$ & $\begin{array}{c}\text { Mixing plant B } \\
\text { Nov. 10, 2014 }\end{array}$ \\
\hline No. 1 $\mathrm{m}^{3}$ blocks & 2 & 2 \\
No. of layers & 1 and 2 & 2 and 3 \\
Layer thickness & $80 \mathrm{~cm}$ and $40 \mathrm{~cm}$ & $40 \mathrm{~cm}$ and $27 \mathrm{~cm}$ \\
\hline
\end{tabular}

\subsection{Material Properties}

Crushed granite was used as coarse aggregate for both of the mixes seen in Table 1. The granite was delivered from Yeoman Glensenda, Scotland, and Aarhus, Denmark, for mix no. 1 and mix no. 2, respectively. Quarry sand from Zealand, Denmark, was used for mix no. 1, and concrete sand from Jutland, Denmark, was used for mix no. 2. All aggregates belonged to environmental class E (DS Standard 2426, 2011). The density and absorption of the aggregates are shown in Table 2.

Figure 2 shows the gradation curves for the aggregates.

Low-alkali Portland cement CEM I 42.5 N was used with fly ash type B4 from Denmark. Two different types of AEA were 
Table 2: Fine and coarse aggregate properties for mix nos. 1 and 2.

\begin{tabular}{l|cc}
\hline & $\begin{array}{c}\text { Density } \\
{\left[\mathrm{kg} / \mathrm{m}^{3}\right]}\end{array}$ & $\begin{array}{c}\text { Absorption } \\
{[\%]}\end{array}$ \\
\hline Quarry sand 0/4 mm, mix no. 1 & 2,630 & 0.4 \\
Concrete sand 0/4 mm, mix no. 2 & 2,640 & 0.1 \\
\hline Granite 4/8 mm, mix no. 1 & 2,630 & 0.4 \\
Granite 4/8 mm, mix no. 2 & 3,030 & 0.4 \\
\hline
\end{tabular}

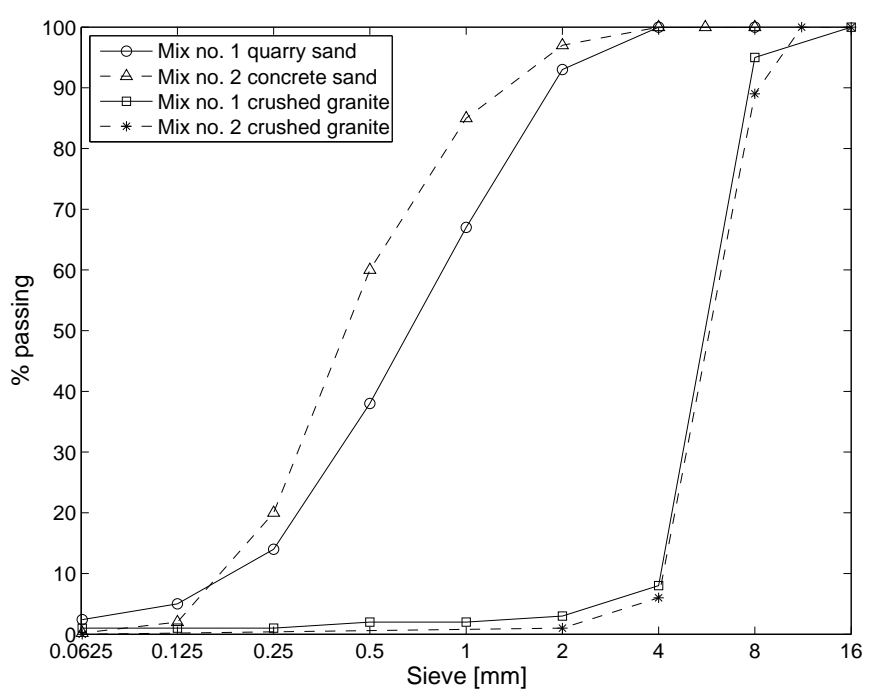

Figure 2: Gradation curves for fine aggregate (quarry or concrete sand) and coarse aggregate (crushed granite).

used at the two mixing plants; however, both types of AEA were combined natural and synthetic.

The materials used for the full-scale implementation were the same as those listed for mix no. 2; in addition a phosphatebased retarder was used.

\subsection{Mixture Proportions}

\subsubsection{Mix Design for Small-Scale Tests}

The mix design used for mix nos. 1 and 2 was mainly the same; only minor corrections in the amount of AEA were made to achieve an air content of $6 \%$ in the fresh pervious concrete. Both mixtures were designed to have a w/c ratio of 0.29 , a fly ash to cement ratio of $20 \%$, and $9.5 \%$ of the mass of coarse aggregate replaced by sand. Furthermore, both mixes were designed to have a void content of $17.5 \%$ in addition to entrained air. Table 3 shows the two mixture proportions.

Table 3: Mix design of $1 \mathrm{~m}^{3}$ PCPC for mix nos. 1 and 2 .

\begin{tabular}{l|cc}
\multicolumn{3}{c}{ Table 3: Mix design of $1 \mathrm{~m}^{3}$ PCPC for mix nos. 1 and 2.} \\
\hline & Mix no. 1 & Mix no. 2 \\
\hline Place & Mixing plant A & Mixing plant B \\
\hline Cement $\left[\mathrm{kg} / \mathrm{m}^{3}\right]$ & 317.6 & 317.6 \\
Fly ash $\left[\mathrm{kg} / \mathrm{m}^{3}\right]$ & 63.5 & 63.5 \\
Water $\left[\mathrm{kg} / \mathrm{m}^{3}\right]$ & 95.2 & 94.1 \\
Air entrainment $\left[\mathrm{kg} / \mathrm{m}^{3}\right]$ & 5.0 & 6.1 \\
Sand $\left[\mathrm{kg} / \mathrm{m}^{3}\right]$ & 122.4 & 122.8 \\
Granite $\left[\mathrm{kg} / \mathrm{m}^{3}\right]$ & $1,291.7$ & $1,488.1$ \\
\hline Density $\left[\mathrm{kg} / \mathrm{m}^{3}\right]$ & $1,895.3$ & $2,092.2$ \\
\hline
\end{tabular}

The air content in the fresh concrete was measured with a press-ur-meter, though studies have indicated that this will cause incorrect readings because air caught in the large voids is also included in the measurement (Kevern et al., 2009). No standards exist for measuring the amount of entrained air in fresh PCPC, so the technique was nonetheless applied and found to provide reasonable results. Boiled, cooled, demineralised water was used to eliminate air bubbles. Mix no. 1 showed a direct correlation between the added amount of AEA and the amount of entrained air read off the press-ur-meter. The added amount of AEA was higher than for regular concrete.

The stiff consistency of pervious concrete prevents evaluating the workability of a given mixture from a slump test. Therefore, the workability of the PCPC mixtures for the small-scale tests was assessed by forming a ball of the PCPC (Tennis et al., 2004). Both mix no. 1 and mix no. 2 showed good cohesion and no excess of water when forming a ball, indicating a good workability.

\subsubsection{Mix Design for Full-Scale Implementation}

The mix design used in the full-scale implementation was basically the same as mix no. 2. However, because transportation from the mixing plant to the construction site took one hour, it was necessary to add a retarder. Table 4 shows the mix design used for the full-scale implementation.

Table 4: Mix design of $1 \mathrm{~m}^{3}$ PCPC for Pearl-Chain Bridge over Vorgod Stream.

\begin{tabular}{l|c}
\hline Place & Mixing plant B \\
\hline Cement $\left[\mathrm{kg} / \mathrm{m}^{3}\right]$ & 317.6 \\
Fly ash $\left[\mathrm{kg} / \mathrm{m}^{3}\right]$ & 63.5 \\
Water $\left[\mathrm{kg} / \mathrm{m}^{3}\right]$ & 88.8 \\
Air entrainment $\left[\mathrm{kg} / \mathrm{m}^{3}\right]$ & 6.1 \\
Retarder $\left[\mathrm{kg} / \mathrm{m}^{3}\right]$ & 7.2 \\
Sand $\left[\mathrm{kg} / \mathrm{m}^{3}\right]$ & 122.6 \\
Granite $\left[\mathrm{kg} / \mathrm{m}^{3}\right]$ & $1,486.1$ \\
\hline Density $\left[\mathrm{kg} / \mathrm{m}^{3}\right]$ & $2,092.0$ \\
\hline
\end{tabular}

\subsection{Preparation of Specimens for Small-Scale Tests}

A total of $4 \mathrm{~m}^{3}$ PCPC was mixed and poured into a concrete truck for each of the two mixes. From here it was placed in the molds applying the smallest possible lift. The molds used to cast the PCPC blocks measured $1,600 \times 800 \times 800 \mathrm{~mm}^{3}$. The height of the molds corresponded fairly well with the maximum thickness of the filling material in the Pearl-Chain Bridge over Vorgod Stream. Table 1 summarizes the layer thickness for the different blocks before a plate compactor with an area of $53 \times$ $35 \mathrm{~cm}^{2}$ and 5,500 vibrations per minute was used on them. The compaction was carried out by moving the plate compactor over the top surface of the PCPC layer in lanes just overlapping each other. The block cast in one layer was compacted two times, while the blocks cast in two and three layers were compacted one time per layer. To improve the bond between the layers, the topside of each layer was raked before casting the overlying layer. Figure 3 shows the appearance of the two blocks with mix no. 1 after the molds were split. 


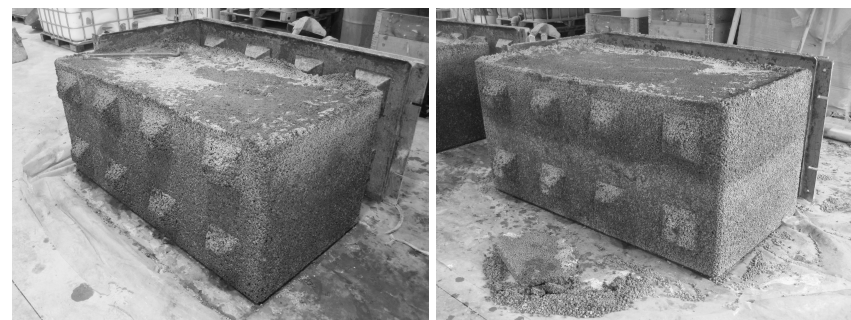

Figure 3: Appearance of PCPC blocks cast with mix no. 1. Left: Block cast in one layer. Right: Block cast in two layers.

The core temperature of the blocks was measured during hardening and a maximum temperature of $51^{\circ} \mathrm{C}$ was achieved after 12 hours.

The concrete blocks were covered with two layers of plastic immediately after casting to prevent moisture evaporation. The plastic was kept on for one week after hardening; subsequently, concrete cores were drilled from the blocks with a specially constructed $800 \mathrm{~mm}$ long diamond drill having an external diameter of $150 \mathrm{~mm}$ and an internal diameter of $143 \mathrm{~mm}$ which enabled drilling all the way through the blocks for a core representing the entire thickness of the block. Nine cores were drilled from each block. Figure 4 shows the appearance of a full core with a length of approximately $650 \mathrm{~mm}$.

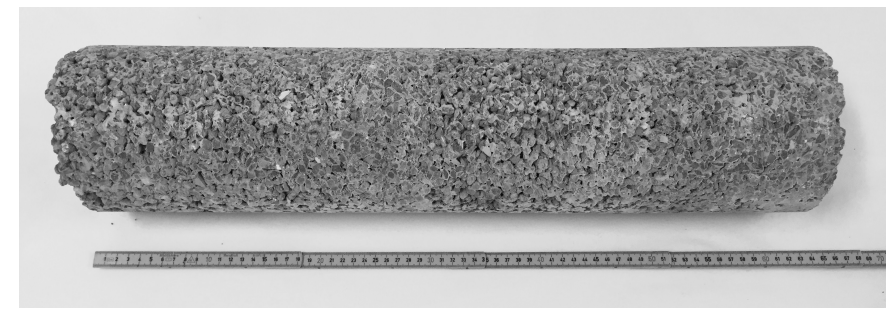

Figure 4: $650 \mathrm{~mm}$ long pervious concrete core drilled from block cast in two layers at mixing plant A. The core is rotated $90^{\circ}$ compared to the drilling direction.

For each block, three full-length cores were used to determine compressive strength and Young's modulus, three to determine splitting tensile strength, and three to determine the variation in void distribution. Each full-length core used for strength tests was cut into two cylinders with a height-todiameter ratio $(h / d)$ of 2 ; one cylinder represented the top of the block and one represented the bottom. Each core used to determine the variation in void content was cut into 6-7 100 mm high specimens throughout the layer depending on the total height of the block. Each specimen was cured in a $50^{\circ} \mathrm{C}$ water basin until reaching an equivalent 28-days age at $20^{\circ} \mathrm{C}$.

Only mix no. 2 was tested for shear strength. A total of 16 prisms were cut from each of the blocks to determine the shear strength. When cutting these prisms, the outer approximately $100 \mathrm{~mm}$ surface was first removed. Figure 5 shows the position from where the prisms were taken. Each prism measured 320 $\times 160 \times 100 \mathrm{~mm}^{3}$.

The upper prisms (U) do not contain any layer interface for any of the two blocks whereas all lower prisms (L) contain one layer interface. The prisms were stored in a $20^{\circ} \mathrm{C}$ water basin

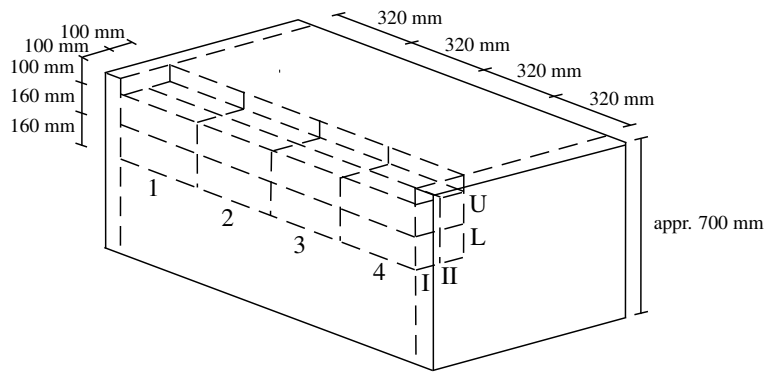

Figure 5: Position and naming of prisms cut for shear strength tests. For clarity, the outer $100 \mathrm{~mm}$ thick surface in front of the specimens is not shown in the figure. This surface was removed before cutting the prisms.

until reaching an equivalent 28 -days age at $20^{\circ} \mathrm{C}$.

\subsection{Preparation of PCPC for Full-Scale Test}

The preliminary results from the small-scale test suggested that the filling material in the Pearl-Chain Bridge should be cast in layers with a thickness of approximately $30 \mathrm{~cm}$ before compaction. Since the maximum placing depth after compaction was $0.9 \mathrm{~m}$, the filling material had to be cast in a total of four layers with each being compacted by the same plate compactor as used in the small-scale tests. A wood formwork was placed in the transverse bridge direction to ensure the correct layer thicknesses. The three lower layers all had a thickness of approximately $25 \mathrm{~cm}$ after compaction, whereas the thickness of the upper layer was only approximately $15 \mathrm{~cm}$. As a result, the upper layer was only compacted once whereas the underlying layers were each compacted twice. Due to the distance between the bridge ends and the center of the bridge, it was necessary to pour PCPC by use of a belt. The fill over the two middle abutments was laid out simultaneously. A protruding reinforcement was installed in the top of the side elements for the concrete top plate being cast at a later stage. Due to this reinforcement, it was not possible to compact the outer $0.5 \mathrm{~m}$ of the two upper layers along the long bridge edge using the plate compactor. Instead, this area was compacted with a hand compactor created from a $200 \times 200 \mathrm{~mm}^{2}$ plate connected to a handle. Figure 6 illustrates how the PCPC filling material was stepwise laid out.

Because of fresh PCPC's stiff consistency, it is not possible to assess its workability from the standard slump cone test. Instead, fresh PCPC mixture workability was determined by assessing the fresh unit weight. When a new PCPC batch arrived, the fresh unit weight was determined in accordance with Procedure A in the ASTM C1688 standard (ASTM Standard C168814a, 2014), by compacting a specified PCPC volume with a standard Proctor hammer. By weighing the mass of the compacted PCPC, the density of the fresh PCPC was calculated. In total, 10 PCPC batches were delivered to the construction site; five to the east end of the bridge and five to the west end. Table 5 shows the fresh unit weight determined for the different batches.

Problems were experienced when placing the third layer of the filling material due to batch no. 4 being too wet. The mixing 

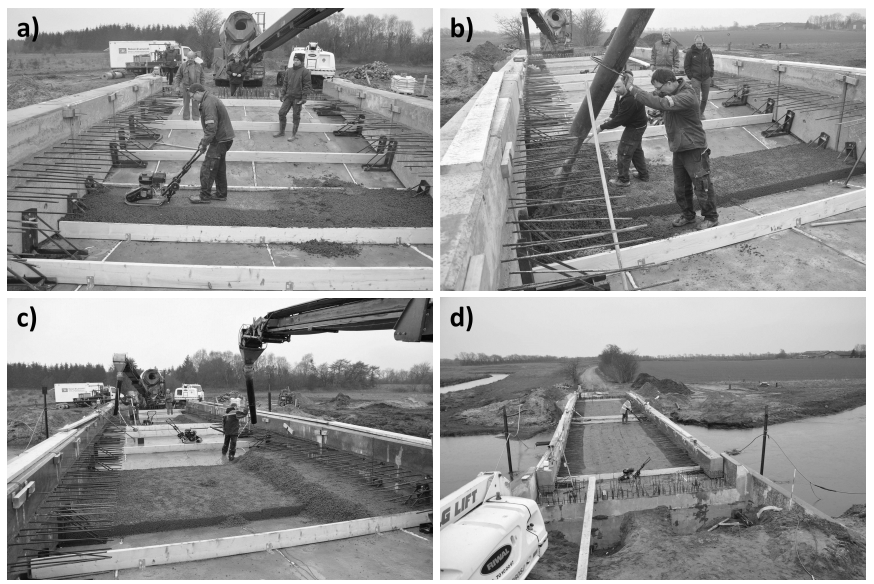

d)

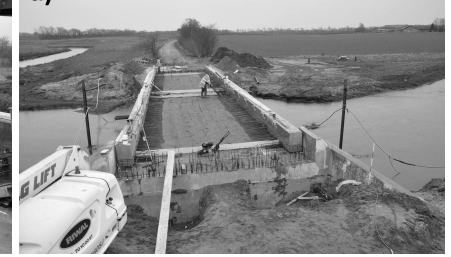

Figure 6: Filling of pervious concrete on Pearl-Chain Bridge over Vorgod Stream. a: compaction of first layer; b: casting of second layer; c: casting of third layer; $\mathrm{d}$ : finishing of fourth layer.

Table 5: Fresh unit weight (UW) of PCPC batches delivered to east and west end of construction site of Pearl-Chain Bridge over Vorgod Stream. UW was not measured for batch no. 3 .

\begin{tabular}{l|cc}
\hline \multirow{2}{*}{ Batch no. } & \multicolumn{2}{|c}{ UW $\left[\mathrm{kg} / \mathrm{m}^{3}\right]$} \\
& East & West \\
\hline 1 & 2,142 & 2,107 \\
2 & 2,171 & 2,089 \\
4 & 2,264 & 2,236 \\
5 & 2,084 & 2,040 \\
\hline
\end{tabular}

plant later explained this shift in consistency with a mistake in the correction of aggregate moisture content. This change is also clear from Table 5 where the unit weight of batch no. 4 is seen to be higher than the remaining material. However, the batch was still placed and this caused a visibly lower void content of the third layer as seen in Figure 7. The PCPC close to the bridge edge is seen to be drier than that close to the bridge center.

Three temperature sensors were placed in the same vertical section over each middle abutment. One sensor was placed below the filling material and two sensors were placed in the two lower layer interfaces. Furthermore, the air temperature was measured. Figure 8 shows the variation in temperature over one of the abutments; as shown, the maximum temperature is only $41^{\circ} \mathrm{C}$.

After emplacement, the filling material was tightly covered with plastic and allowed to cure for 15 days before the plastic was removed. Immediately afterwards, 12 cores with a diameter of $100 \mathrm{~mm}$ and a length of $300 \mathrm{~mm}$ were drilled before casting the concrete top plate. Figure 9 shows the location of the cores taken from the filling material. The location of the cores had to be close to the middle abutments where the thickness of the filling material was largest.

Each core was wrapped in two layers of plastic to prevent moisture evaporation. Subsequently, each core was cut to a length of $200 \mathrm{~mm}$ and placed in a $20^{\circ} \mathrm{C}$ water basin until reaching an equivalent 28 -days age at $20^{\circ} \mathrm{C}$. At that time, the void content of the cores was determined, six cores were tested in

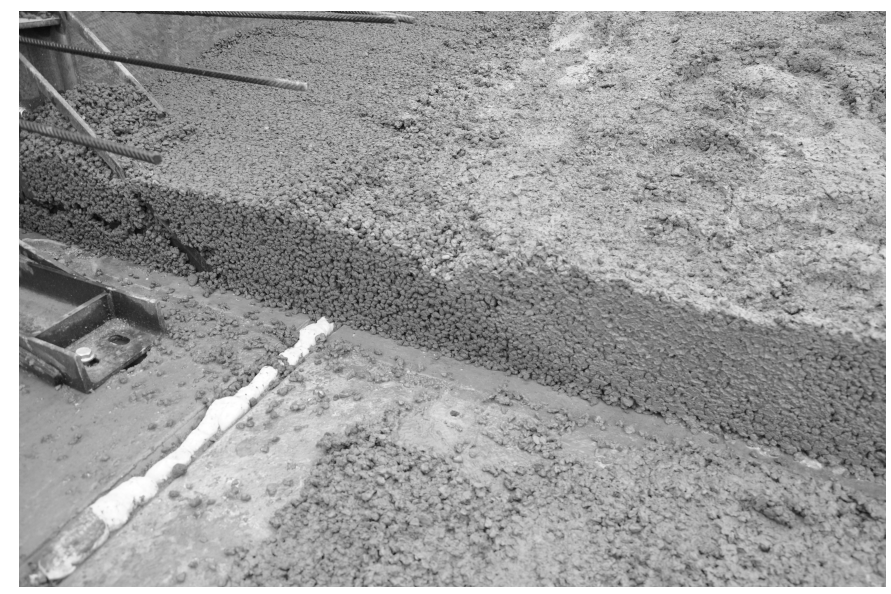

Figure 7: Difference in consistency in PCPC placed in third layer of filling material on Pearl-Chain Bridge over Vorgod Stream. PCPC close to the bridge center (right hand side of photo) is considerably wetter than PCPC close to the bridge edge (left hand side of photo).

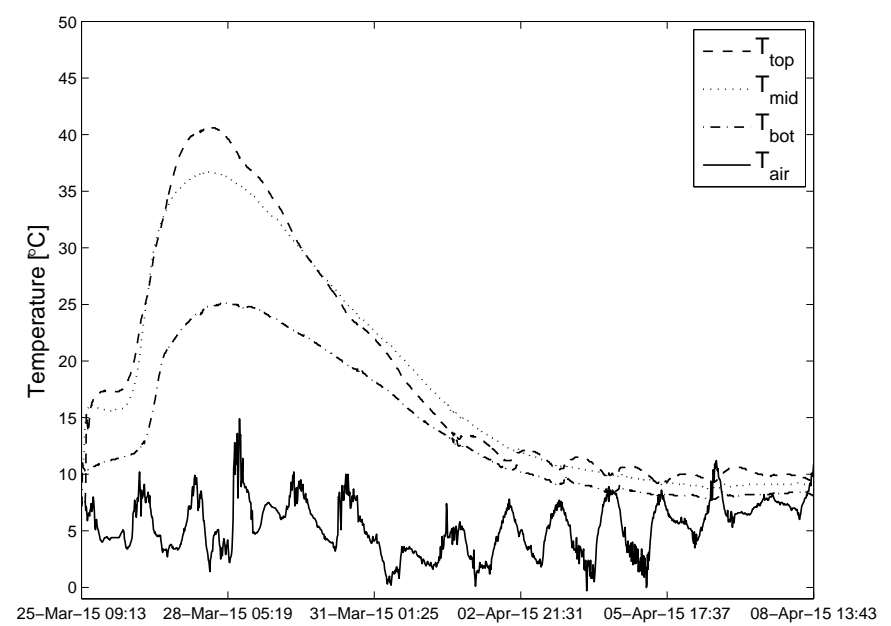

Figure 8: Temperature variation over one abutment in PCPC filling material on Pearl-Chain Bridge over Vorgod Stream. The temperature profile measured over the other abutment looks similar.

compression, and six cores were tested in splitting tension.

\subsection{Testing Procedure}

\subsubsection{Determination of Void Content}

The void content of the specimens was determined from a water displacement setup based on Archimedes' principle. The specimens were submerged and weighed under water, then oven-dried at $40^{\circ} \mathrm{C}$ for 24 hours, and finally weighed above water, whereby it was possible to calculate the void content, $P[\%]$, as

$$
P=\left(1-\frac{m_{40^{\circ} \mathrm{C}}-m_{s w}}{\rho_{w} V_{t o t}}\right) \cdot 100 \%
$$

where $m_{40}{ }^{\circ} \mathrm{C}[\mathrm{kg}]$ is the mass of the oven-dried specimen after 24 hours, $m_{s w}[\mathrm{~kg}]$ is the mass of the specimen submerged in water, $\rho_{w}\left[\mathrm{~kg} / \mathrm{m}^{3}\right]$ is the water density, and $V_{t o t}\left[\mathrm{~m}^{3}\right]$ is the total volume of the specimen. 


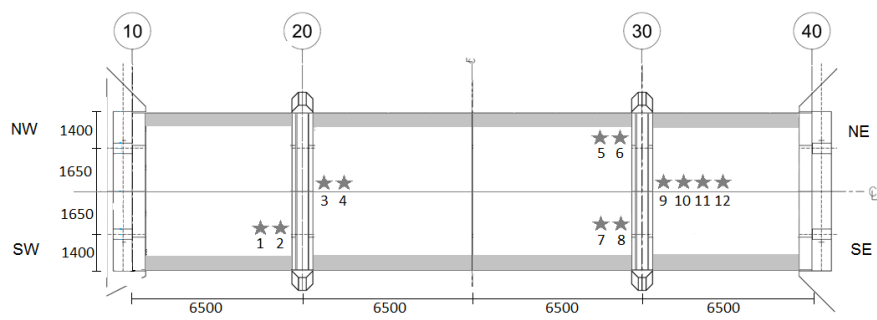

Figure 9: Top view of Pearl-Chain Bridge over Vorgod Stream with location (stars) of cores drilled from filling material. Dimensions are in $\mathrm{mm}$.

\subsubsection{Determination of Strength and Stiffness}

The compressive strength and Young's modulus were determined from the same test setup. No standards exist regarding strength-testing procedures for pervious concrete; hence modified versions of the Danish Standard (DS) 12390-3 (DS Standard 12390-3, 2009), and the International Organization for Standardization (ISO) 6784 standard (ISO Standard 6784, 1982), were used. The compressive test was performed on a TONI 3,000 kN machine with a load rate of $7 \mathrm{kN} / \mathrm{s}$ for specimens with a diameter of $143 \mathrm{~mm}$, and a load rate of $3 \mathrm{kN} / \mathrm{s}$ for specimens with a diameter of $100 \mathrm{~mm}$. When measuring the strain of the specimen, rigid rings were tightly mounted around the top and bottom and two extensometers were placed between the rings. Following this, the correlation between load and deformation was logged during compression. When determining Young's modulus, the main difference from the ISO 6784 standard (ISO Standard 6784, 1982), was that no reloading took place and the modulus of elasticity was determined from the first loading. The Young's modulus was only determined for mix no. 2 specimens.

The splitting tensile strength was determined from the DS 12390-6 standard (DS Standard 12390-6, 2002), on a TONI $3,000 \mathrm{kN}$ machine with a load rate of $4 \mathrm{kN} / \mathrm{s}$ for the specimens with a diameter of $143 \mathrm{~mm}$, and a load rate of $2 \mathrm{kN} / \mathrm{s}$ for those with a diameter of $100 \mathrm{~mm}$. Hard fiberboard plates measuring $4 \times 10 \times 300 \mathrm{~mm}^{3}$ were placed below and above the specimen.

The shear strength was determined from the test setup shown in Figure 10 inspired by Schmit et al. (2011) with the load applied over a $160 \times 100 \mathrm{~mm}^{2}$ shear plane. The test was carried out on an Instron $100 \mathrm{kN}$ machine with a load rate of 0.4 $\mathrm{mm} /$ minute.

\section{Results and Discussion}

\subsection{Results and Discussion of Small-Scale Tests}

\subsubsection{Density and Void Content for Small-Scale Tests}

Figure 11 shows the variation in dry density with void content for a total of 12 specimens cut from each block.

A strong linear correlation with $\mathrm{R}^{2}$-values greater than 0.85 between the void content and the density of the specimens is seen.

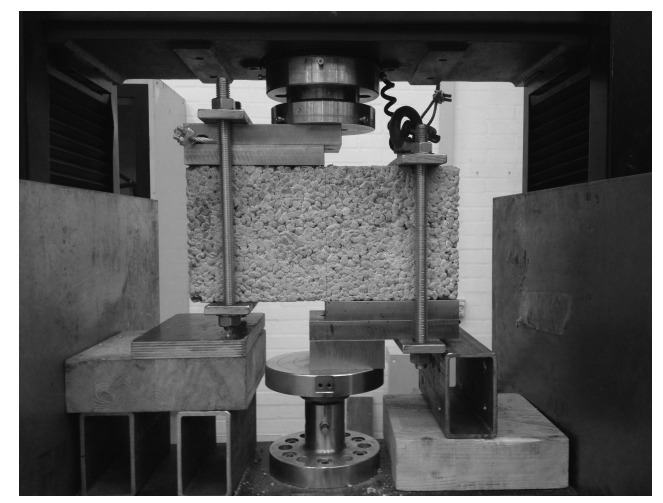

Figure 10: Shear strength test setup. Specimen measures $160 \times 100 \times 320$ $\mathrm{mm}^{3}$.

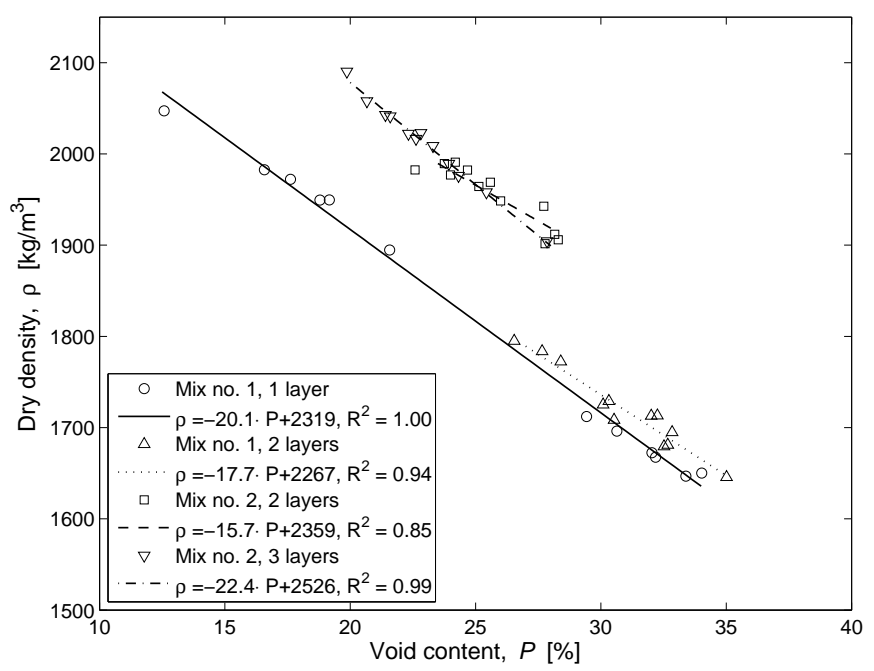

Figure 11: Variation in dry density with void content for cores drilled from blocks. Note the scale on the axes.

\subsubsection{Vertical Variation in Void Content for Small-Scale Tests}

The total height of the hardened block varied between 650 $\mathrm{mm}$ and $750 \mathrm{~mm}$ dependent on the number of layers. The vertical variation in void content through a block was determined for blocks cast in one, two, and three layers. Figures 12, 13 and 14 show the variation in void content with depth for these three scenarios.

Considering Figure 12, the variation in vertical void content for the block cast in one layer is seen to vary between approximately $5 \%$ close to the top of the block and $33 \%$ close to the bottom of the block. Furthermore, it is evident that the plate compactor influence has a limited range after which the void constant aligns with depth. The estimated range is marked with a vertical black line that corresponds to a depth of approximately $40 \mathrm{~cm}$. The points below this depth are not believed to be representative for the variation in the layer void content; hence, they are omitted from the further analysis. Previous studies such as Haselbach and Freeman (2006) have suggested a linear variation in the vertical void content with depth. The compaction method is expected to influence the results; however, the present study indicates a strong logarithmic tendency 


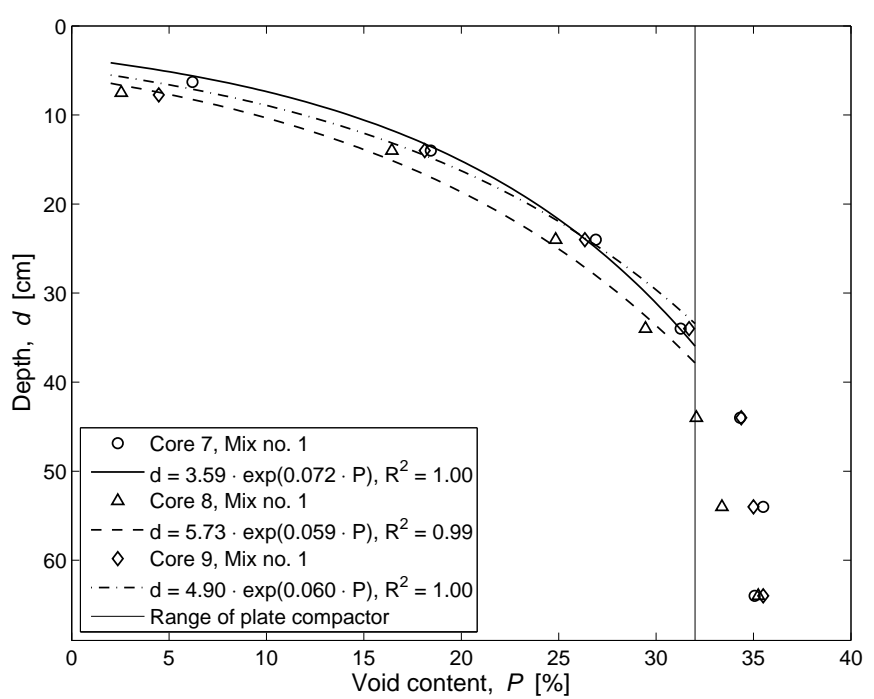

Figure 12: Variation in void content of block cast in one layer with mix no. 1. A depth of $0 \mathrm{~cm}$ corresponds to the surface of the block where the compaction took place. The total height of the block after compaction was $69 \mathrm{~cm}$.

in the vertical void variation with depth, with $\mathrm{R}^{2}$-values of 0.99 and 1.00 .

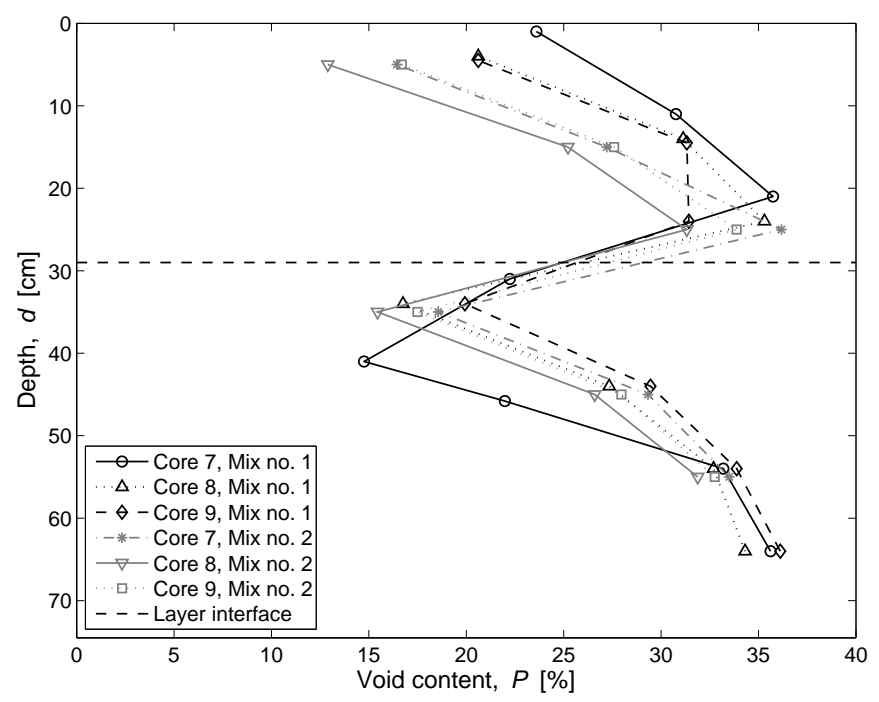

Figure 13: Variation in void content of block cast in two layers with mix nos. 1 and 2. A depth of $0 \mathrm{~cm}$ corresponds to the surface of the block where the compaction took place. The total height of the blocks after compaction was 70 $\mathrm{cm}$ and $65 \mathrm{~cm}$.

Considering Figure 13, only three void content measurements are obtained for each of the layers for the blocks cast in two layers; hence, it is not possible to comment on whether the vertical variation in void content is also logarithmic. Nevertheless, it can be seen that the variation has decreased compared to the block cast in one layer. The vertical void content is now varying between $15-20 \%$ at the top of a layer and $30-35 \%$ at the bottom of a layer.

Considering Figure 14, the variation in void content has decreased even further when the block is cast in three layers. The

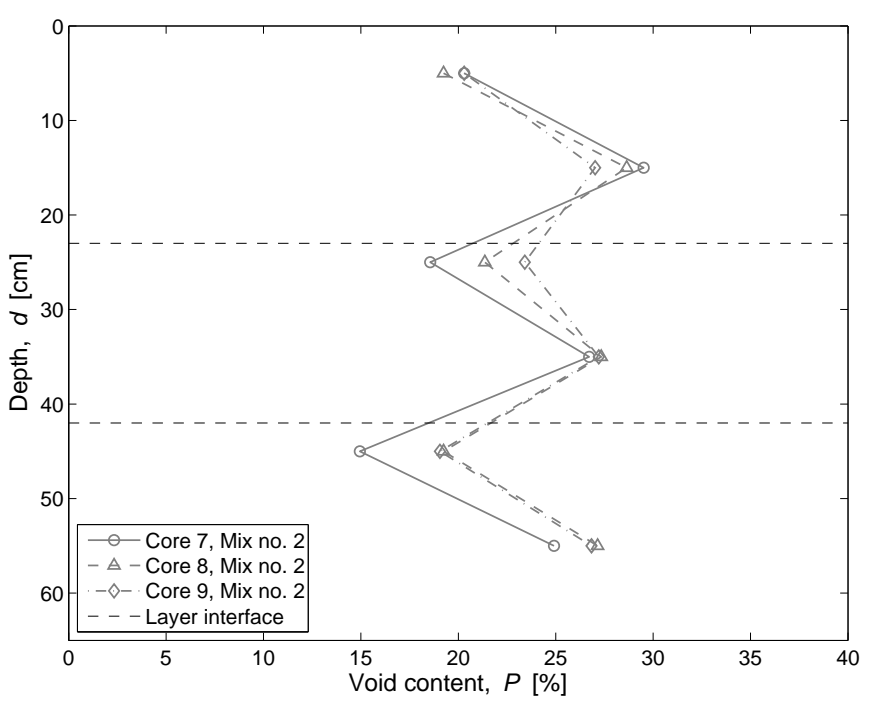

Figure 14: Variation in void content of block cast in three layers with mix no. 2. A depth of $0 \mathrm{~cm}$ corresponds to the surface of the block where the compaction took place. The total height of the block after compaction was $65 \mathrm{~cm}$.

variation in each layer is now reduced to $\sim 20 \%$ at the top of the layer and $\sim 30 \%$ at the bottom of the layer. Moreover, it can be seen from Figures 13 and 14 that the void variation in underlying layers is not influenced by casting and compacting overlying layers.

The same specimens that were used to determine the vertical variation in void content were subsequently tested in compression at an equivalent 28-days age at $20^{\circ} \mathrm{C}$. The rationale behind this was that these specimens, which had $h / d=100 / 143 \sim 0.7$, had a more homogeneous void content than the usual test specimens with $h / d=2$. For this reason, a better understanding of the actual correlation between void content and compressive strength was expected. Figure 15 shows the variation in the compressive strength of the $h / d=0.7$ specimens from the one layer block from mix no. 1 and the two layer block from mix no. 2. For clarity, the data from the other two blocks is not included, but provide similar results.

Figure 15 suggests there is a strong linear correlation between the void content and the compressive strength of the specimen. All results have $\mathrm{R}^{2}$-values greater than 0.95 .

All strength tests used to characterize strength properties of the PCPC mixes were performed on cylinders with $h / d=2$. The void content of all cylinders was determined as described in Section 3.5.1 prior to the strength testing. Table 6 shows the void contents of the cores drilled for strength tests from the block cast in one layer from mix no. 1. The table illustrates the void content of top cylinders and the corresponding bottom cylinders.

Table 6: Average void content of specimens with $h / d=2$ from block used for strength determination cast in one layer with mix no. 1.

\begin{tabular}{l|cccccc}
\hline & \multicolumn{7}{|c}{ Core no. } \\
Void content [\%] & 1 & 2 & 3 & 4 & 5 & 6 \\
\hline Top of layer & 19.2 & 17.6 & 21.6 & 16.6 & 12.6 & 18.8 \\
Bottom of layer & 34.0 & 32.0 & 33.4 & 30.6 & 29.4 & 32.2 \\
\hline
\end{tabular}




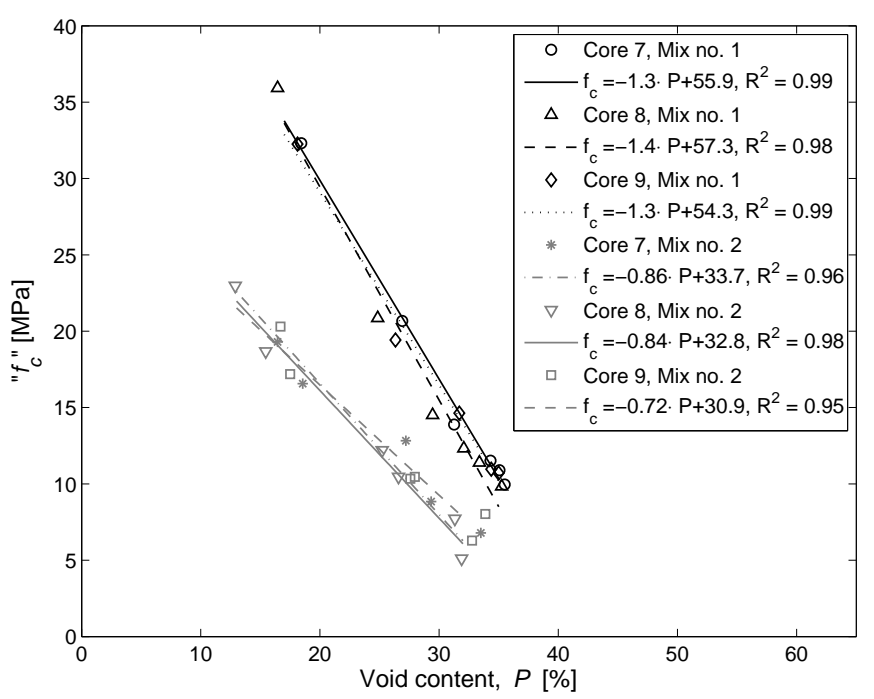

Figure 15: Variation in compressive strength with void content for block cast in one layer with mix no. 1 and two layers with mix no. 2 . " $f_{c}$ " is measured on specimens with $h / d=0.7$.

According to Table 6, the void content of the top cylinders from the block cast in one layer with mix no. 1 is $13-22 \%$. However, analyzing the depth between $d=0-300 \mathrm{~mm}$ in Figure 12 reveals that the void content within each cylinder actually varies between $5-33 \%$. Hence, the void content used to characterize and connect with a certain strength property is an average value that does not cover the variation in void content within the cylinder itself. The same is true when comparing the void content of bottom specimens, and also when comparing cores drilled from the remaining three blocks even though the error is minimized when increasing the number of layers. Because the strength properties determined for cylinder specimens with $h / d=2$ are typically connected with the average void content of the specimen, there is a miscorrelation between the strength variation with void content. In fact, the strength properties presented express those of the part of the specimen with the highest void content.

\subsubsection{8-days Compressive Strength for Small-Scale Tests}

Figure 16 shows the 28-days compressive strength of the specimens drilled from the four blocks, comparing that of those taken from the top of the block with that of those taken from the bottom of the block. The compressive strength values of pervious concrete should always be seen in the light of the void content since these two parameters are strongly correlated. Therefore the figure also shows the average void content of the specimens.

Considering "Mix no. 1, 2 layers", "Mix no. 2, 2 layers", and "Mix no. 2, 3 layers", the top and bottom specimens within each block have void contents that are statistically equivalent. As shown in Figure 16, this also explains why the compressive strengths for bottom and top specimens for each block are statistically equivalent. The average 28-days compressive strength for "Mix no. 2, 3 layers" is 9.1 MPa, whereas it is 7.7 MPa for "Mix no. 2, 2 layers", and 6.9 MPa for "Mix no. 1, 2 layers".

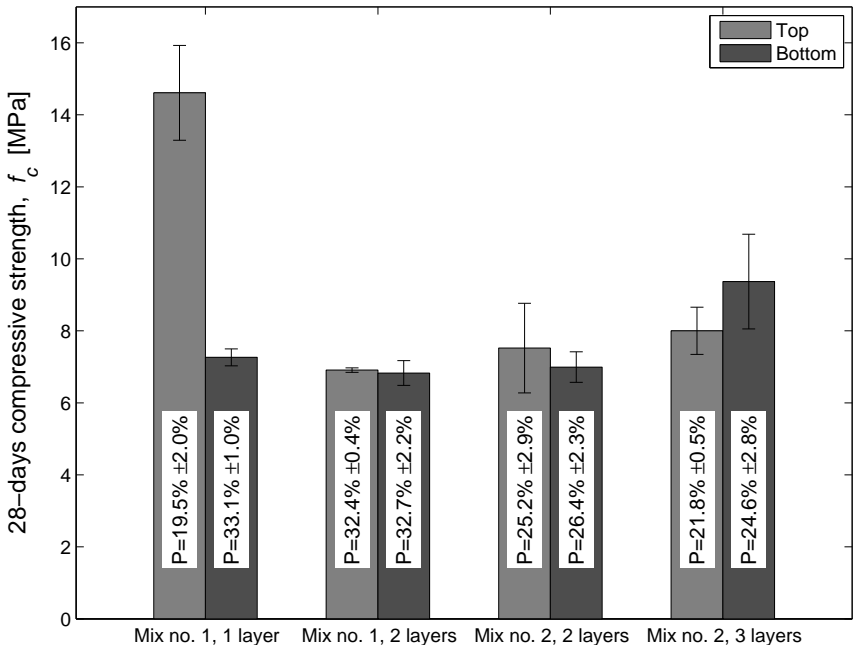

Figure 16: 28-days compressive strength, $f_{c}$, of top and bottom specimens from mix nos. 1 and 2 . The figure also shows the corresponding average void contents of the specimens and the standard deviation of the void content and the compressive strength.

The decrease in compressive strength between the blocks is believed to be directly correlated to the corresponding increase in void content; see Figure 16.

Considering "Mix no. 1, 1 layer", the void content of top and bottom specimens varies. The average 28-days compressive strength of the bottom specimens is $7.3 \mathrm{MPa}$, which is comparable with the specimens from "Mix no. 1, 2 layers" that also have void contents in the same order of magnitude. The average 28-days compressive strength of the top specimens is $14.6 \mathrm{MPa}$ which is twice as high as that of the bottom specimens. This is explained by the correspondingly lower void content, which is in the same order of magnitude as the top specimens from "Mix no. 2, 3 layers"; nevertheless, the average 28-days compressive strength is significantly higher. The explanation might be that even though the average void content is the same, a relatively large variation within the specimens themselves is found as discussed in connection with Table 6 .

\subsubsection{8-days Young's Modulus for Small-Scale Tests}

The 28-days Young's modulus was determined from the stress-strain curves obtained from the compression tests of the specimens from mix no. 2. An example of such a stress-strain curve can be found in Figure 17.

Due to the high void content of the pervious concrete specimens, it was rather difficult to fasten and fix the rings for strain measurements to make sure they would not move during the compressive tests. In some cases the stress-strain curves revealed that the rings had moved. Figure 18 shows the variation in Young's modulus with void content for the blocks cast with mix no. 2.

For Figure 18, the results are omitted from tests where the ring system is believed to have moved. Nevertheless, a big scattering of the results is still observed and no clear dependency on the void variation is observed, possibly because the range of void contents considered is relatively narrow. However, an in- 


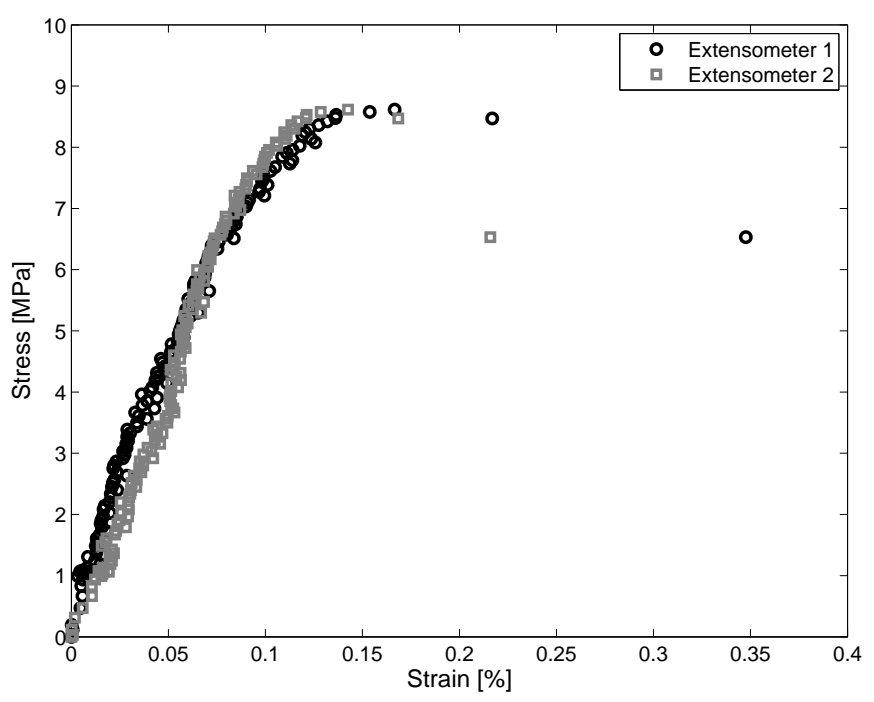

Figure 17: Stress-strain curve for compression test of a top specimen from the block cast in three layers with mix no. 2. Two extensometers, nos. 1 and 2, were fastened to log the strains.

dication of the size of Young's modulus can be found from the results.

\subsubsection{8-days Splitting Tensile Strength for Small-Scale Tests}

Figure 19 shows the 28-days splitting tensile strength of the specimens drilled from the four blocks. The figure compares those taken from the top of the block with those taken from the bottom. The figure also shows the average void content of the specimens.

Considering "Mix no. 2, 2 layers" and "Mix no. 2, 3 layers", the top and bottom specimens are seen to have void contents that are statistically equivalent. This also explains why the splitting tensile strengths for bottom and top specimens from each block are statistically equivalent. The average 28-days splitting tensile strength for "Mix no. 2, 2 layers" is $1.1 \mathrm{MPa}$, whereas it is 1.2 MPa for "Mix no. 2, 3 layers". The increase in splitting tensile strength is believed to be directly correlated to the corresponding decrease in void content. However, the standard deviation of the results, especially with mix no. 2 , reveals that they are subject to a certain scattering.

Considering "Mix no. 1, 1 layer" and "Mix no. 1, 2 layers", the void variation between the top specimens and bottom specimens is seen to be larger than for the blocks cast with mix no. 2, especially for the block cast in one layer where the void content of the bottom specimens is twice as high as for the top specimens. The corresponding average 28-days splitting tensile strength for the top specimens is $1.5 \mathrm{MPa}$, whereas it is $0.6 \mathrm{MPa}$ for the bottom specimens.

Overall, the observed difference between specimens from the different blocks is believed to be caused by the variation in void content. The higher the void content, the lower the splitting tensile strength.

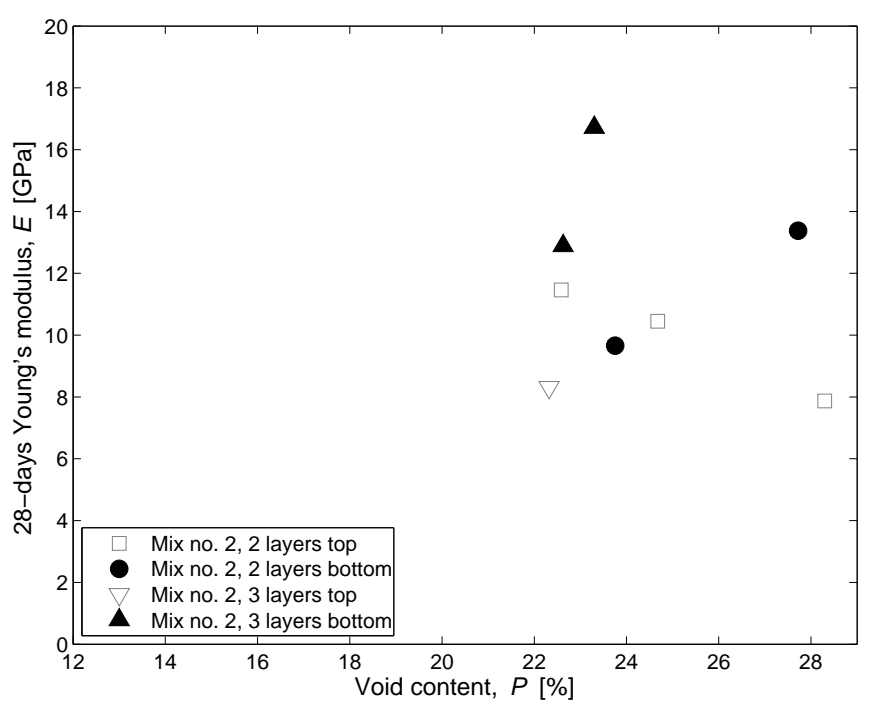

Figure 18: Variation in 28-days Young's modulus with void content for specimens cast in two layers and three layers with mix no. 2 .

\subsubsection{8-days Shear Strength for Small-Scale Tests}

The 28-days shear strength of the prisms cut from the blocks in two and three layers from mix no. 2 is shown in Figures 20 and 21 .

The results are divided into upper (U) and lower (L) specimens, and front (I) and back (II) specimens. Reference is made to Figure 5 for the positions of these specimens.

From Figure 21, a linear variation in shear strength with void content is observed; the same tendency is not found from the results in Figure 20. From the shear strength determined for the block cast in two layers, there is a clear difference between those determined from the upper specimens and from the lower specimens. The upper specimens have an average shear strength that is $0.5 \mathrm{MPa}$ higher than that of the lower specimens even though the difference in void content is only one percentage point. The reason for this difference can be that the lower specimens contain a layer interface, which is not the case for the upper specimens. However, the same tendency is not observed for the specimens from the block cast in three layers.

\subsection{Results and Discussion of Full-Scale Test}

Table 7 shows the void content and the corresponding compressive strength and splitting tensile strength of cores taken from the PCPC filling material on the Pearl-Chain Bridge over Vorgod Stream.

As seen in Table 7, the void content of most of the cores is considerably lower than the design void content. This also means that the strength values are considerably higher than those determined from the small-scale tests. It is believed that the reason for this is that PCPC batch no. 4 was too wet. The cores tested were drilled $300 \mathrm{~mm}$ vertically down in the filling material from the top, and subsequently, the upper 50-70 $\mathrm{mm}$ were removed; hence, a big part of each core represents the third layer which is known to be too wet causing the PCPC skeleton to collapse. If it had been possible to take out sam- 


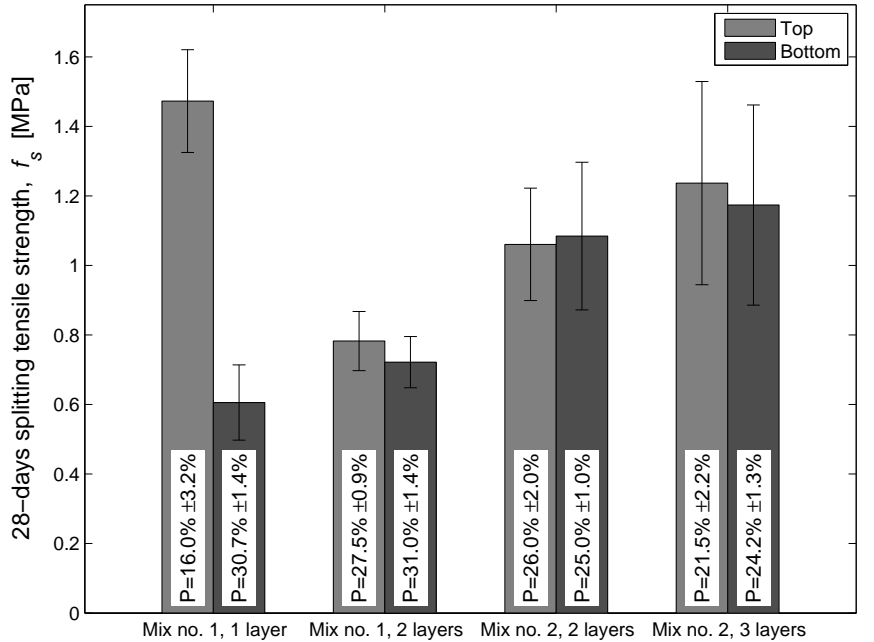

Figure 19: 28-days splitting tensile strength, $f_{s}$, of top and bottom specimens from mix no. 1 and 2 . The figure also shows the corresponding average void contents of the specimens and the standard deviation of the void content and the splitting tensile strength.

Table 7: 28-days compressive strength, $f_{c}$, and 28-days splitting tensile strength test, $f_{s}$, for cores from PCPC filling material on Pearl-Chain Bridge over Vorgod Stream.

\begin{tabular}{l|ccc}
\hline Core no. & Void content $[\%]$ & $f_{c}[\mathrm{MPa}]$ & $f_{s}[\mathrm{MPa}]$ \\
\hline 1 & 3.8 & 25.0 & - \\
3 & 2.6 & 28.8 & - \\
5 & 14.2 & 17.4 & - \\
7 & 8.4 & 22.6 & - \\
9 & 5.8 & 26.1 & - \\
11 & 4.0 & 22.5 & - \\
\hline 2 & 3.7 & - & 2.7 \\
4 & 3.0 & - & 2.4 \\
6 & 14.5 & - & 1.4 \\
8 & 4.3 & - & 3.4 \\
10 & 4.7 & - & 3.4 \\
12 & 3.3 & - & 3.6 \\
\hline
\end{tabular}

ples from the first two PCPC layers, it is expected that the void content would have been considerably larger.

The influence of hand compaction of the two upper layers closest to the bridge edges is clear from the void content of core nos. 5 and 6 that were taken close to the northern bridge edge, below the protruding reinforcement, as seen in Figure 9. The void content of core nos. 5 and 6 is higher than that of the remaining cores and it approaches the design void content. This also affects the strength properties, which, according to Table 7, are lower than for the remaining cores.

The strength properties of all cores meet the requirements to PCPC fill in Pearl-Chain Bridges. It should be noted that the increase in strength properties of the PCPC filling material compared to the design values has no negative influence on the static function of the bridge.

The experiences drawn from the present study emphasize the need for general regulations on quality control of pervious concrete. No such European regulations exist. An assessment of whether a given batch is too dry or too wet is subjective and

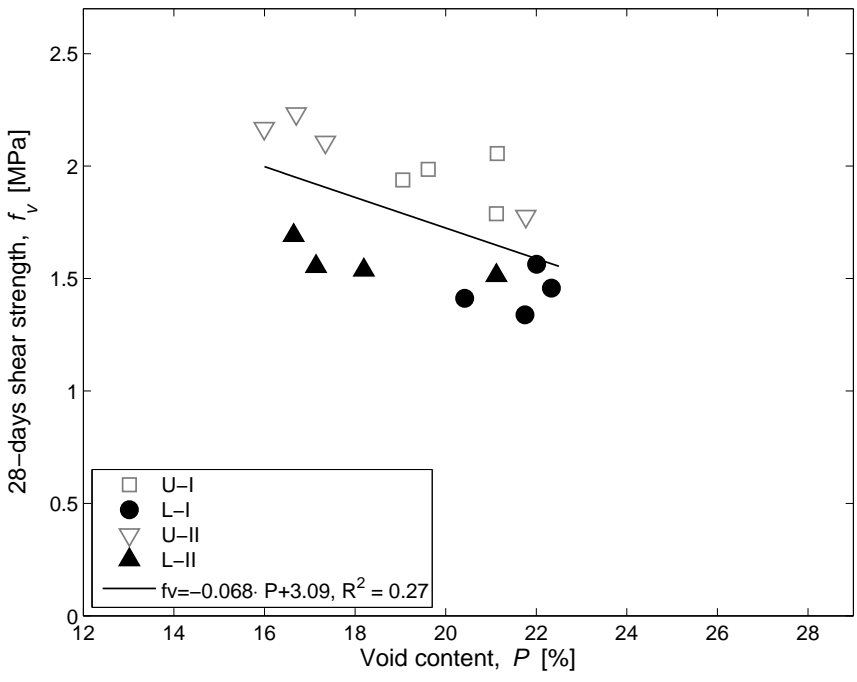

Figure 20: Variation in 28-days shear strength with void content for blocks cast in two layers with mix no. 2.

therefore impossible to use as a quality control. Even though the authors assessed that PCPC batch no. 4 was too wet, any less-experienced personnel will not be able to do so. Therefore, a measurable quality routine should be adapted. Since 2013, the American Concrete Institute (ACI) has recommended that the difference in fresh unit weight between mixture proportion and a given batch be used as quality control. According to the ACI 522.1M-13 standard (ACI Standard 522.1M-13, 2013), a batch is only accepted if the fresh unit weight is within \pm 80 $\mathrm{kg} / \mathrm{m}^{3}$ from the submitted mixture proportion. An equivalent quality control would in all probability have prevented batch no. 4 from being cast on the Pearl-Chain Bridge over Vorgod Stream since a clear increase in fresh unit weight was measured, as commented previously.

\section{Conclusions}

In this study, pervious concrete was used as filling material with a total depth of up to $0.9 \mathrm{~m}$ in a $26 \mathrm{~m}$ long Pearl-Chain Bridge. The planning of the full-scale implementation was based on small-scale tests where the variations in void content and strength properties were investigated to find the most appropriate layer thickness. The main conclusions from the study can be summarized as follows:

1. The variation in void content throughout a layer compacted from above follows a logarithmic tendency with the lowest void content at the top of the layer and the highest void content at the bottom of the layer.

2. It is possible to cast several pervious concrete layers on top of each other without influencing the void content and strength properties of underlying layers.

3. Layer thicknesses exceeding $27 \mathrm{~cm}$ before compaction cause inhomogeneous specimens with respect to void content when the layer is compacted from above. With a layer thickness of $27 \mathrm{~cm}$, a void content of $20-30 \%$ was obtained throughout each layer. 


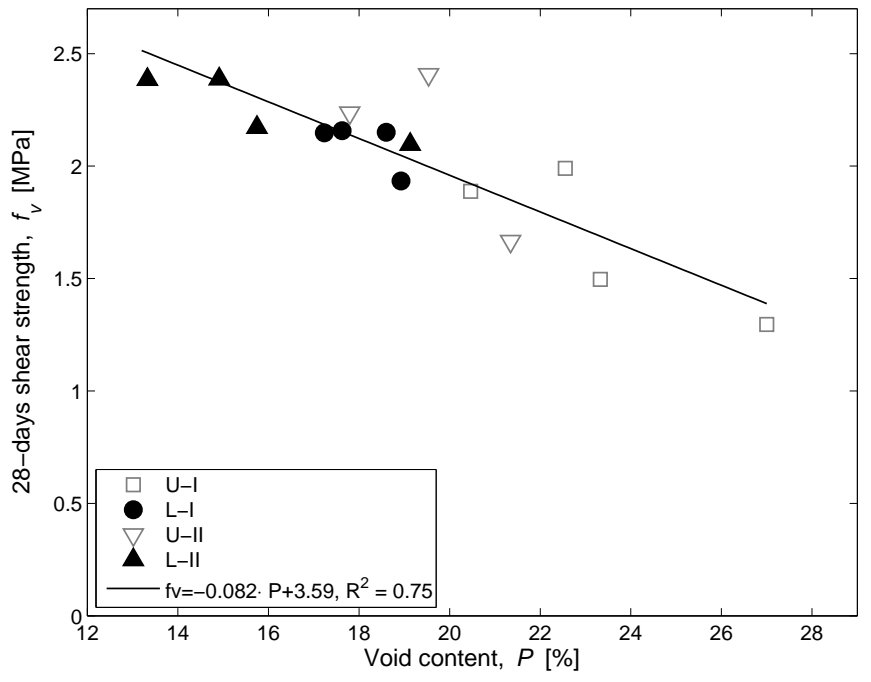

Figure 21: Variation in 28-days shear strength with void content for blocks cast in three layers with mix no. 2.

4. A 28-days compressive strength of $9.1 \mathrm{MPa}$ and a 28-days splitting tensile strength of $1.2 \mathrm{MPa}$ were obtained with a pervious concrete mix containing no admixtures except from air entrainment and with a layer thickness of $27 \mathrm{~cm}$ and a void content of $20-30 \%$ through the layer. Moreover, a linear variation in the 28-days shear strength with void content was found for the same pervious concrete mix and layer thickness. The shear strength values varied between 1.3 MPa and 2.4 MPa for void contents between $27 \%$ and $13 \%$.

5. Determination of Young's modulus of pervious concrete is connected with a significant scattering because of difficulties in installing the testing equipment due to the voids.

6. The strength properties determined for a cylinder specimen with $h / d=2$ are often related to the average void content of the specimen. This causes a miscorrelation of the strength variation with void content when the specimen is compacted from above because the strength properties actually relate to the part of the specimen with the highest void content; typically, the lower part of the specimen.

7. There is a linear correlation with $\mathrm{R}^{2}$-values of 1.0 between void content and 28-days compressive strength when the compressive strength is measured on cylindrical specimens with $h / d=0.7$, which have a more homogeneous void distribution than cylinders with $h / d=2$.

8. It is possible to implement pervious concrete as filling material in arch bridges, including Pearl-Chain Bridges. However, quality control regulations are needed to ensure proper consistency and workability of PCPC in the field so the results after placing are satisfying. Restrictions on the variation in fresh unit weight seem to be an appropriate quality control.

\section{Acknowledgments}

The authors wish to thank Innovation Fund Denmark for supporting this project and the Danish concrete mixing plants Wewers and IBF for their contributions.

\section{References}

ACI 522.1M-13. (2013) "Specification for Pervious Concrete Pavement". ACI Standard, Reported by ACI Committee 522, ISBN-13: 978-0-87031-848-1. ASTM Standard C666/C666M-03. (2008) "Standard Test Method for Resistance of Concrete to Rapid Freezing and Thawing". ASTM International, West Conshohocken, PA, DOI: 10.1520/C0666_C0666M-03R08.

ASTM Standard C1688/C1688M-14a. (2014) "Standard Test Method for Density and Void Content of Freshly Mixed Pervious Concrete". ASTM International, West Conshohocken, PA, DOI: 10.1520/C1688_C1688M-14A.

Crouch, L.K., Pitt, J. and Hewitt, R. (2007) "Aggregate Effects on Pervious Portland Cement Concrete Static Modulus of Elasticity". Journal of Materials in Civil Engineering ASCE, Vol. 19, No. 7, pp. 561-568, DOI: 10.1061/(ASCE)0899-1561(2007)19:7(561).

DS Standard 1991-2. (2003) "Eurocode 1: Actions on structures - Part 2: Traffic loads on bridges". Danish Standards, Denmark.

DS Standard 1991-2 DK NA. (2003) "Annex A (Normative) Load models for classification and evaluation of load carrying capacity". Danish Standards, Denmark (In Danish).

DS Standard 2426. (2011) "Concrete - Materials - Rules for application of EN 206-1 in Denmark". Danish Standards, Denmark.

DS Standard 12390-3. (2009) "Testing hardened concrete - Part 3: Compressive strength of test specimens". Danish Standards, Denmark.

DS Standard 12390-6. (2002) "Testing hardened concrete - Part 6: Tensile splitting strength of test specimens". Danish Standards, Denmark.

Halding, P.S., Hertz, K.D., Petersen, N.E.V. and Kennedy, B. (2015a) "Assembly and lifting of Pearl-Chain Arches". In Proceedings of fib Symposium 2015, Copenhagen, Denmark.

Halding, P.S., Hertz, K.D., and Schmidt, J.W. (2015b) "Precast Pearl-Chain concrete arch bridges". Journal of Engineering Structures, Vol. 103, pp. 214-227.

Haselbach, L.M. and Freeman, R.M. (2006) "Vertical Porosity Distributions in Pervious Concrete Pavement". ACI Materials Journal, Vol. 103, No. 6, pp. $452-458$.

Henderson, V. and Tighe, S. (2012) "Evaluation of pervious concrete pavement performance in cold weather climates". International Journal of Pavement Engineering, 13:3, pp. 197-208, DOI: 10.1080/10298436.2011.572970.

ISO Standard 6784. (1982) "Concrete - Determination of static modulus of elasticity in compression”. International Standard.

Kevern, J.T., Schaefer, V.R., Wang, K. and Suleiman, S.T. (2008) "Pervious Concrete Mixture Proportions for Improved Freeze-Thaw Durability". Journal of ASTM International, Vol. 5, No. 2, JAI101320.

Kevern, J.T., Wang, K. and Schaefer, V.R. (2009) "Test Methods for Characterizing Air Void Systems in Portland Cement Pervious Concrete". Journal of ASTM International, Vol. 6, No. 9, DOI:10.1520/JAI102451.

National Ready Mixed Concrete Association (NRMCA). (2004) "Freeze-Thaw Resistance of Pervious Concrete", NRMCA, Silver Spring, MD, USA.

Regional variation of extreme rain in Denmark - a new analysis 1979-2005 (2006). København: Pamphlet no. 28, IDA Wastewater Commission, ISBN: 87-7923-502-6 (In Danish).

Schaefer, V.R., Wang, K., Suleiman, M.T. and Kevern, J.T. (2006) "Mix Design Development for Pervious Concrete in Cold Weather Climates". A report from the National Concrete Pavement Technology Center, Iowa State University, Ames, IA, USA.

Schaefer, V.R. and Kevern, J.T. (2011) "An Integrated Study of Pervious Concrete Mixture Design for Wearing Course Applications". A report from the National Concrete Pavement Technology Center, Iowa State University, Ames, IA, USA.

Schmit, H.K.M., Reid, E. R. E., Beatty, A.A., Stratford, T.J. and Bisby, L.A. (2011) "Shear Strength of Concrete at Elevated Temperature". In Proceedings of Application of Structural Fire Engineering 2011, Prague, Czech Republic. 
Tennis, P.D., Leming, M.L. and Akers, D.J. (2004) "Pervious Concrete Pavements". EB302.02, Portland Cement Association, Skokie, IL, and National Ready Mixed Concrete Association, Silver Spring, MD, USA. 